\title{
Processo de transição para uma posição de liderança: um estudo com mulheres
}

\author{
Transitioning process to an organizational \\ leardership position: a study with women
}

\section{Catarina Brandão ${ }^{1}$ Fábio Santos ${ }^{2}$ (D) Sara Peres ${ }^{3}$ (D)}

\begin{abstract}
${ }^{1}$ Autora para correspondência. Faculdade de Psicologia e de Ciências da Educação, Universidade do Porto (Porto). Portugal. catarina@fpce.up.pt ${ }^{2}$ Faculdade de Psicologia e de Ciências da Educação, Universidade do Porto (Porto). Portugal. fabiodosantoss94@gmail.com, saraperes95@gmail.com
\end{abstract}

RESUMO | Parecem ser vários os desafios, emoções e constrangimentos com os quais as mulheres se deparam para alcançarem posições de liderança nas organizações. Nesse seguimento, este estudo tem como objetivos descrever o processo de transição de mulheres para uma posição de liderança em contexto organizacional e as representações de jovens mulheres sobre o mesmo. De forma a concretizar os objetivos definidos foram realizados dois estudos. $O$ estudo 1 recorreu a entrevistas semiestruturadas a mulheres que viveram recentemente o processo de transição. No estudo 2 aplicou-se um questionário com perguntas abertas a 30 jovens mulheres universitárias. Os dados foram sujeitos a análise de conteúdo categorial. Os resultados permitiram identificar três fases no processo de transição para uma posição de liderança Aprendizagem, Autonomização e Consolidação. Permitiu ainda identificar que ao longo do processo de transição as mulheres experienciam dificuldades a nível do assumir as novas funções, obter reconhecimento do papel de líder e mudanças nas relações. As representações das jovens mulheres vão ao encontro das vivências das mulheres, revelando-se conscientes do papel dos estereótipos de gênero na liderança feminina.

PALAVRAS-CHAVE: Mulheres. Liderança. Processo de transição. Estereótipos de gênero.

\begin{abstract}
Women face challenges and constraints in reaching leadership positions in organizations. This research aims to describe the process of transition of women to a leadership position in an organizational context and the representations of young women regarding that process. In order to achieve this, two studies were conducted. Study 1 used semi-structured interviews with women who recently experienced the transition process. In study 2 , a questionnaire with open questions was applied to 30 young university women. Data were subjected to categorical content analysis. The results allowed us to identify three phases in the process of transition to a leadership position - Learning, Empowerment and Consolidation. It was also identified that throughout the transition process women experience difficulties assuming the new role, gaining recognition of the leading role and changes in relationships. Representations of young women meet these women's experiences and we see they are aware of the role of gender stereotypes in female leadership.
\end{abstract}

KEYWORDS: Women. Leadership. Transitioning process. Gender stereotypes. 


\section{Introdução}

A desigualdade de gênero permanece um fator preponderante no trajeto das mulheres para alcançarem posições de liderança (Grant Thornton's International Business Report, 2019). Os estereótipos levam a que as mulheres sintam que devem provar constantemente que merecem a posição de liderança que ocupam, ao que se associa pressão, ansiedade e stress (Santos, Peres, \& Brandão, 2018). O estudo que aqui se apresenta visa contribuir para a exploração compreensiva da vivência das mulheres em contexto organizacional (Dória \& Brandão, 2016), especificamente quando ocupam ou poderão vir a ocupar posições de liderança formal. Não adotando a visão tradicional da investigação de gênero que foca as diferenças entre homens e mulheres, procuramos identificar representações que poderão traduzir causas implícitas e explícitas de diferenças de gênero, assim como mecanismos através dos quais estas se perpetuam (Costa, Breda, Pinho, Bakas, \& Durão, 2016). No âmbito deste estudo, consideramos os processos dinâmicos de liderança que são requeridos a quem ocupa posições hierárquica de chefias ou supervisão, às quais estão associadas autoridade formal.

\section{Mulheres nas organizações e processos de liderança}

A presença das mulheres no mercado de trabalho é cada vez maior. Em Portugal, desde 2015 que a percentagem de mulheres que integra a população empregada é superior a 48,5\% (PORDATA, 2020)', verificando-se ainda que as mulheres representam mais de $60 \%$ da população ativa com nível de escolaridade superior desde 2013. Ainda em Portugal, a Comissão para a Cidadania e a Igualdade de Género (2017) aponta que em 2016 as mulheres eram maioritárias entre o pessoal administrativo $(65,7 \%)$ e trabalhadores/as dos serviços pessoais, de proteção e segurança e vendedores/as $(64,4 \%)$ e entre os/as especialistas das atividades intelectuais e científicas (59,2\%). Contudo, traduziam apenas cerca de um terço $(35,9 \%)$ dos/as representantes do poder legislativo e de órgãos executivos, dirigentes, diretores/as e gestores/as executivos/as. De facto, no que se refere a posições de liderança nas organizações, e apesar da presença crescente de mulheres nestas posições, a sua percentagem a nível mundial é ainda bastante reduzida, sendo apenas de 29\% em 2018 (Grant Thornton's International Business Report, 2019).

Alguma literatura aponta diferenças de gênero no exercício da liderança, associando as mulheres a um estilo de liderança transformacional (Bass \& Avolio, 1994), que enfatiza a importância dos valores e da visão partilhada (Martin, 2015). Ao mesmo tempo, Eagly e colegas (Eagly \& Johannesen-Schmidt, 2001; Eagly, Johannesen-Schmidt, \& Engen, 2003) chamam a atenção para a influência dos papéis de gênero na liderança, ou seja, para a influência das regras sobre como alguém se deve comportar como homem ou mulher no exercício da liderança em contexto organizacional. Referem que as mulheres adoptam o estilo de liderança transformacional devido à pressão que é exercida nesse sentido e aos seus próprios esforços para se acomodarem aos papéis de gênero sobre a liderança. Coerentemente, à luz das perspetivas contemporâneas, as disparidades observadas no exercício da liderança devem-se principalmente a fatores contextuais e situacionais (Daniel \& Moudic, 2010). A literatura tem abandonado uma leitura categorial do exercício da liderança, que identifica características típicas da liderança feminina e masculina, focando antes os fatores contextuais ou situacionais que podem estar na génese de disparidades a nível do exercício da liderança, nomeadamente o papel da educação e a perpetuação de estereótipos que reforçam uma cultura organizacional masculina (Daniel \& Moudic, 2010).

Um relatório produzido pela Catalyst em 2002, que recolheu dados junto de 500 mulheres e 132 homens (ocupando posições seniores) de 20 países da Europa (incluindo Portugal) indicava que as mulheres europeias consideravam que os estereótipos e preconceitos sobre os papéis e as competências das mulheres eram a principal barreira para o seu progresso, seguida de perto pela falta de modelos, falta de experiência em gestão, o compromisso com as responsabilidades familiares e pessoais e a falta de orientação (i.e., de mentoring). O impacto dos estereótipos de gênero no processo de alcançar uma posição de liderança emergiu novamente no estudo que a mesma organização produziu em 2006. 
Apesar dos estereótipos de gênero serem uma das principais dificuldades com as quais as mulheres se deparam no contexto de trabalho (assim como fora dele) (Piterman, 2008), nomeadamente no trajeto para posições de liderança, é possível identificar outros desafios e constrangimentos. Considere-se, nomeadamente, a dificuldade sentida na gestão da relação trabalho-família (Brandão \& Lopes, 2017) e as normas sociais e culturais impostas às mulheres (Haile, Emmanuel, \& Dzathor, 2016), que podem culminar na inibição em investir em áreas de estudo ou formações que proporcionem carreiras em posições de liderança. Existem ainda muitas organizações que são, no geral, mais inflexíveis para acomodar muIheres em posições de chefia, quando as mesmas têm filhos ou apresentam necessidades especiais (Aparna, 2014). Note-se, contudo, que muitas das mulheres que participaram no estudo desenvolvido pela Catalyst (2002) subiram na carreira enquanto geriam responsabilidades pessoais: $75 \%$ eram casadas e destas, $73 \%$ tinham um parceiro com trabalho a tempo integral e $63 \%$ tinham filhos.

Há mais de 30 anos atrás, Kanter (1989) chamou a atenção para o potencial transformador da presença de mulheres em posições de liderança, indicando que poderia reforçar positivamente relações entre mulheres em contexto organizacional, levando a que estas avaliassem de forma mais positiva as características das mulheres subordinadas em relação aos requisitos organizacionais. Neste sentido, diversidade (e inclusão) de gênero nas organizações encerra em si potencial de mudança do status quo.

\section{Transição para posições de liderança}

Quando se fala de um processo de transição, seja a nível de carreira, de país, de relações amorosas, ou outras, importa considerar a variedade de alterações significativas que ocorrem na vida do sujeito que experiencia a transição (Sargent \& Schlossberg, 1988). Os processos de transição acarretam sempre alterações na vida dos indivíduos, que importa considerar de forma a compreender futuros comportamentos, atitudes e desempenhos.
Quem ocupa posições de chefia em contexto de organizacional é obrigado a gerir situações no quotidiano que estão inteiramente ligadas às pessoas que estão sob a sua supervisão e que frequentemente traduzem processos de transição (e.g., licenças de maternidade ou paternidade das/dos suas/seus funcionárias/os, casamentos, divórcios, auxílio a familiares doentes). Contudo, não se tem considerado a natureza do próprio processo de transição para uma posição que requer processos de liderança, embora se reconheça a dificuldade associada a este desafio para quem o vivencia e para as organizações (Keller \& Meaney, 2018). É importante que os indivíduos nesta situação equacionem o seu próprio processo de transição para uma nova posição organizacional e que tem associada a si responsabilidades específicas, nomeadamente a nível da coordenação de pessoas. Essa mudança poderá levar à perceção de alterações nas suas vidas, nomeadamente, de novas regras, novos papéis, novas relações e distanciamentos de outrora colegas que se tornam subordinados. Isto poderá alterar a forma como orientam as suas vidas e alcançam os seus próprios objetivos.

Na medida em que a literatura é omissa no que se refere à natureza do processo de transição para uma posição de liderança em contexto organizacional (apesar de proliferarem trabalhos sobre como preparar um líder para uma nova posição), recorremos a um trabalho seminal sobre a integração de um trabalhador numa organização (e que permanece uma referência principal acerca deste processo), para meIhor perceber a natureza desta transição. Esse modelo, proposto por Porter, Lawler, and Hackman (1975), sistematiza a integração de um novo membro numa organização em três fases: "entrar", "adequar" e "estabilizar". O modelo postula que numa primeira fase do processo - entrar - a pessoa recebe informação sobre a organização, apesar de ainda não ser efetivamente um membro desta. Na segunda fase - adequar - o indivíduo torna-se membro da organização, iniciando-se um período de trabalho experimental, que é promovido com o objetivo de adaptar o novo trabalhador à organização. Numa última fase - estabilizar - o novo membro já se encontra adaptado ao contexto da organização, alterando os seus valores, relações e comportamentos. 
As transições, ainda que desejadas, podem levar a sentimentos de preocupação e confusão por parte de quem as enfrenta, obrigando à mobilização de estratégias de coping. Schlossberg (2011) avança com um modelo de transição que assenta em quatro S (Situation, Self, Support e Strategies for coping), que procura ajudar o indivíduo a gerir um processo de transição. No que diz respeito ao primeiro $\mathrm{S}$ - Situation (i.e., situação), a autora aponta que é necessário compreender que tipo de situação está a ser enfrentada e a forma como a pessoa a vê, ou seja, se existem outras situações de stress em simultâneo e se a pessoa considera o momento da transição de forma positiva ou negativa. $\mathrm{O}$ segundo $\mathrm{S}$ - Self, refere-se à capacidade de o indivíduo gerir a transição - se é otimista, resiliente, ágil para lidar com a existência de ambiguidade. $\mathrm{O}$ terceiro $\mathrm{S}$ Support, sustenta que o apoio existente, por parte de outros, durante o processo de transição, é fundamental para o bem-estar do indivíduo. Por fim, o quarto S - Strategies for coping, define que não existe uma estratégia de coping milagrosa para gerir a situação, e que cada indivíduo deve identificar as estratégias que Ihe permitem gerir a transição da forma que melhor respeite o seu bem-estar.

Considerando a natureza desafiante dos processos de transição e a ausência de literatura acerca do processo de transição de mulheres para posições organizacionais formalmente associadas ao exercício de liderança, este estudo visa (1) descrever o processo de transição de mulheres para uma posição de liderança organizacional, identificando (i) as fases desse processo e (ii) as dificuldades associadas ao mesmo. Paralelamente, considerando os constrangimentos experienciados pelas mulheres para alcançar posições de liderança organizacional, pretendemos (2) descrever as representações de jovens mulheres acerca deste processo.

\section{Método}

Esta investigação adota uma abordagem qualitativa, considerando a ausência de literatura acerca do processo de transição para posições de liderança, particularmente no que se refere a mulheres. De forma a dar resposta aos objetivos de investigação definidos foram realizados dois estudos, adotando-se procedimentos que visaram assegurar a qualidade das inferências realizadas ${ }^{2}$. Os dados foram recolhidos em Portugal.

\section{Estudo 1}

Para concretizar o primeiro objetivo de investigação recolheu-se informação junto de duas participantes do gênero feminino, pertencentes à geração millenial (dado ser a mais representativa do mercado de trabalho de hoje e no futuro próximo) e que tivessem vivenciado o processo de transição para uma posição de liderança num período compreendido entre seis e 12 meses. Optamos por este período de modo a que as participantes tivessem uma perceção mais pormenorizada sobre este processo. As participantes foram selecionadas de forma intencional através da rede de contactos dos autores.

A participante 1 (P1) integra uma empresa de informática. Tem 37 anos de idade, licenciatura em ciências de computadores, e assumiu o cargo de liderança há cerca de sete meses, sendo liderada por um chefe de departamento. Ocupava anteriormente uma posição de liderança, em que assumia responsabilidades relacionadas com o desenvolvimento, avaliação e acompanhamento dos elementos da sua equipa. A participante 2 (P2) integra uma empresa na área da construção civil. Tem 29 anos de idade, mestrado em engenharia civil, e assumiu o cargo de liderança na empresa há cerca de seis meses, tendo como supervisor directo o chefe de departamento.

Para coleta de dados optou-se pela entrevista semiestruturada, de forma a permitir que as participantes relatassem, de forma detalhada, vivências associadas ao processo de transição para uma posição de liderança. Para orientar a entrevista, utilizamos um guião de entrevista com cinco questões de resposta aberta (e.g., "fale-me como foi o processo de transição para esta nova função"). O guião de entrevista foi constituído de modo a compreender como era a perceção das participantes acerca do trabalho antes do processo de transição e as suas vivências após o processo de transição para uma posição de liderança. De forma a validar o guião realizou-se um estudo piloto com uma participante

${ }^{2}$ Consultar Santos, Peres e Brandão (2018), onde se discutem os desafios associados ao estudo da liderança feminina. 
mulher, que ocupava uma posição de liderança em contexto organizacional há cerca de 10 anos.

As entrevistas tiveram lugar na casa das participantes, em horário pós-laboral, de modo a que não existissem constrangimentos para as mesmas. Não se registaram interrupções ou distrações no seu decurso. As participantes assinaram a declaração do consentimento informado, que assegurava o seu anonimato, explicitava os objetivos do estudo e pedia autorização para a gravação do áudio da entrevista. As entrevistas tiveram uma duração média de 20 minutos e nove segundos, sendo transcritas e validadas pelas entrevistadas.

\section{Estudo 2}

Para a concretização do segundo objetivo de investigação recolheu-se informação junto de 30 estudantes universitárias, com idades compreendidas entre os 20 e os 33 anos ( $M=23.00, D P=2.59)$. Entre as participantes, 22 tinham uma licenciatura, sete 0 mestrado e uma encontrava-se a frequentar o ensino superior. As participantes nunca tinham estado envolvidas num processo de transição para posições de liderança organizacional. Cerca de $80,0 \%$ das participantes conheciam uma mulher que se encontrava numa posição de liderança e 20,0\% não conhecia.

Recorreu-se a um questionário com perguntas de resposta aberta, para que as participantes elaborassem, de forma mais completa, as suas perceções sobre o objeto de estudo. O questionário contava com três perguntas de resposta aberta que pretendiam descrever as perceções face ao fenómeno estudado (e.g., «Como pensa que é vivido por uma mulher o processo de transição para uma posição de liderança?»); e debriefing final, no qual era dado feedback às participantes sobre o estudo. $\mathrm{O}$ questionário foi igualmente sujeito a um estudo piloto.

Os questionários foram aplicados online, sendo disponibilizados na plataforma Google Docs durante três dias e divulgados através da rede social Facebook. Incluíram igualmente o consentimento informado.

\section{Análise da informação recolhida}

Os dados recolhidos foram sujeitos a análise de conteúdo categorial, de acordo com os princípios definidos por Bardin (2011), sendo o corpus de análise constituído pela totalidade dos dados qualitativos recolhidos. A unidade de registo adotada foi o tema, sendo a unidade de contexto o documento onde a mesma se inseria. Foram definidas categorias dedutivas a partir da revisão da literatura, e categorias indutivas, decorrentes dos dados empíricos. O sistema de categorização final conta com quatro categorias de primeiro nível e 13 categorias de segundo nível. O processo de gestão, organização e análise dos dados qualitativos foi feito com recurso ao NVivo11 e 12 (QSR), software que se tem demonstrado útil no processo de desenvolver um pensamento profundo sobre dados qualitativos (Brandão, 2015).

\section{Descrição e Discussão dos Resultados}

\section{Processo de transição para uma posição de lide- rança por mulheres}

Sendo as participantes mulheres que tinham assumido recentemente uma posição de liderança, é importante descrever a sua função anterior, para que possamos perceber o seu processo de transição para a função atual.

Antes de ser promovida para a atual função, P1 já ocupava na organização uma posição de liderança, sendo esta de nível inferior e com menor estruturação. As suas principais funções incluíam a gestão de uma equipa de analistas programadores numa empresa de informática. Estando as suas responsabilidades intimamente ligadas com o desenvolvimento, avaliação e acompanhamento dos elementos da sua equipa, a principal dificuldade que sentia era mantêlos motivados, devido às particularidades do trabaIho. Ao ocupar o novo posto de chefia na organização, P1 substituiu um trabalhador que ia sair da empresa. O seu supervisor direto é o chefe de departamento. Lidera um conjunto de chefes de equipa, pelo que os membros da equipa de P1 também eles são líderes. 
Por sua vez, P2 assumia anteriormente na organização a função de adjunta de direção de obra, o que implicava ter um supervisor direto, responsável pela obra. As suas responsabilidades eram ao nível de questões técnicas e qualquer trabalho que fosse solicitado pela chefia direta. A participante não sentia que o seu trabalho fosse desafiante, uma vez que, apesar de considerar importante aquilo que fazia, sabia que se cometesse algum erro tinha um supervisor que assumiria o problema. O posto que passou a ser ocupado por si não era ocupado por ninguém, sendo que a mudança de função implicou que P2 se tornasse responsável por novos projetos. O seu supervisor direto é o chefe do departamento, tendo como subordinados trabalhadores das obras, muitas vezes subcontratados pela empresa.

\section{Etapas do processo de transição}

A análise dos dados das duas participantes permitiunos diferenciar três fases sequenciais no processo de transição para a sua posição de liderança: a fase de Aprendizagem, a fase de Autonomização e a fase de Consolidação. A fase de Aprendizagem representa o momento inicial do processo em que as participantes aprendem a desempenhar a função associada ao cargo de liderança que vão ocupar. No caso de P1, esta fase ocorreu com o acompanhamento da pessoa que ocupava a posição anteriormente e que estava de saída da empresa:

"fase em que estamos os dois ainda presentes na empresa, portanto a pessoa ainda não saiu e está-me a ensinar, está-me a passar tudo o que tem"

Neste caso, a fase de aprendizagem coincidiu com uma passagem de trabalho (do anterior líder para P1). A organização recorre a um trabalhador experiente que, no processo de saída da organização, forma a trabalhadora que o irá substituir. Sendo esta uma estratégia frequentemente operacionalizada pelas organizações quando se dão processos de subsituição, nota-se ainda assim que este momento inicial é de alguma confusão para a participante, uma vez que estavam duas pessoas presentes na organização, sem se saber exatamente qual dos dois estava efetivamente a assumir a função:

"ainda estão as duas pessoas, parece [que] é um bocado confuso quem é que está a assumir a função"
Ou seja, apesar de o acompanhamento por alguém mais experiente nesta fase ser percecionado como positivo, representa igualmente algum ruído, na medida em que a participante não sabia exatamente como agir. Sentia que se devia envolver para poder aprender e estar preparada para assumir a função, mas ao mesmo tempo, ainda havia outra pessoa oficialmente responsável pelo cargo:

"para mim é a mais complicada, porque é a sensação de não me quero meter já nisto tudo porque a outra pessoa ainda está presente, mas ao mesmo tempo tenho que começar a pegar já eu nas rédeas porque de um dia para o outro a responsabilidade é toda minha e é preciso saber as coisas"

Esta vivência remete-nos para os desafios associados a termos um papel que é assumido simultaneamente por duas pessoas, ao mesmo tempo que as fronteiras de cada um estão em mudança - um dos actores desempenha um papel que vai abandonar (o supervisor que assegura a formação de quem o vai substituir) e o outro actor está a identificar os contornos do papel cujo desempenho está a iniciar.

No caso de P2 a transição aconteceu de forma distinta, na medida em que não foi substituir alguém, mas tornou-se responsável por novos projetos. Assim, apesar de ter colegas a ocupar o mesmo tipo de cargo, não teve uma pessoa responsável por orientá-la para que fosse possível assumir autonomamente o desempenho da sua nova função, o que também implicou desafios:

"muita dificuldade em assimilar tudo o que havia para fazer ou que poderia haver, nesse caso, e um bocadinho "andar de carroça à frente dos bois" porque já estava a tentar antever todos os problemas que pudessem existir"

P2 descreve esta fase como tendo sido difícil, parecendo ter-se sentido perdida na imensidão de novas funções e responsabilidades:

"no início existiu uma fase muito má porque quando soube que ia ficar encarregue sozinha por duas obras achei que seria responsabilidade a mais para mim e que não tinha tempo para estar preparada o suficiente para lidar com essa situação" 
Conforme se percebe, a fase de Aprendizagem pode dar-se com ou sem acompanhamento. Sendo certa a pertinência de apoio em processos de transição, conforme referido por Schlossberg (2011), a vivência desta fase sem uma rede de apoio, nomeadamente na forma de um tutor, poderá implicar uma pressão maior por não se saber o que se terá de fazer e ter de aprender sozinha ou de forma mais autónoma as exigências da nova função. As participantes procuravam perceber o que teriam de fazer e como se posicionarem na nova função. Esta fase inicial é mesmo descrita como sendo a mais difícil de todo o processo, devido ao facto de a pessoa ainda não estar confortável no seu novo papel e de ainda não saber como desempenhá-lo:

"não é frustração, mas é uma sensação muito estranha, para mim sempre foi a fase pior" (P1)

"Essa fase foi muito má, muito stress" (P2)

A segunda fase do processo é a fase de Autonomização, que traduz o período de adaptação das participantes à função. Nesta fase as participantes assumiram efectivamente o cargo de liderança e iniciaram o desempenho das tarefas de forma autónoma:

"há outra fase (...) "sim, isto é a sério"; estou sozinha, já
não tenho o outro suporte" (P1)

"quando efetivamente comecei a exercer a função de ficar responsável pelas duas obras" (P2)

Nesta fase as participantes parecem ter uma noção mais clara da função e daquilo que o cargo implica, procurando adaptar-se ao mesmo. Esta fase implicou perceber como desempenhar e planear as tarefas e, ao mesmo tempo, perceber quais as alterações que decorreram a nível relacional com colegas, subordinados e superiores:

"pronto é esta fase um bocado a conquistar ali outra vez as pessoas, a perceber o meu espaço, a perceber o espaço delas a perceber ali aquele espaço mais informal que às vezes temos, que notamos que deixa de existir." (P1)

Emergem dúvidas sobre como fazer, a quem recorrer e como se comportar na posição de liderança. Estas dúvidas podem derivar da perceção de ter de fazer tudo corretamente, que parecem considerar como inerente à posição de liderança e terem subordinados dependentes do seu trabalho:
"Como é que eu vou fazer? Vou conseguir fazer? (...) vou? Que tempo é que eu tenho? Quem é que eu devo consultar cá dentro quando tenho dúvidas?" (P1)

"senti muito o peso da responsabilidade, não queria que nada falhasse" (P2)

A última fase do processo é a fase de Consolidação. Nesta fase as participantes já se sentiam adaptadas à sua nova função e revelavam um novo modo de funcionamento e maior estabilidade:

"depois é passado algum tempo já nos adaptamos, adaptamo-nos todos à situação nova em que estamos (...) e as coisas correm normalmente" (P1)

"neste momento acho que já me habituei um pouco a que as coisas sejam assim" (P2)

Apesar disso, nesta fase as participantes ainda não se sentem capazes de prever e planear completamente o trabalho, bem como todas as dificuldades que possam surgir, o que pode justificar-se com o facto de ainda não terem concluído um ano nesta nova função:

"não estou no ritmo em que já consiga dizer que consigo ter tudo muito bem planeado e tudo muito bem definido" (P1)

"ainda não estou na fase em que consigo prever as dificuldades que estão para vir" (P2)

\section{Dificuldades do processo de transição}

As participantes identificaram três principais dificuldades no seu processo de transição: assumir plenamente as novas funções; obter reconhecimento pelo seu papel de líder; e mudanças nas relações. No que alude ao assumir plenamente as novas funções há referência à diversidade das tarefas a desempenhar e a responsabilidade associadas às mesmas, bem como a pressão de desempenho resultante do novo posto de trabalho, que parece estar associada à necessidade de demonstrar valor e profissionalismo:

"muita dificuldade em assimilar tudo o que havia para fazer ou que poderia haver" (P2)

"senti muito o peso da responsabilidade, não queria que nada falhasse" (P2) 
Outra dificuldade referida foi obter reconhecimento pelo seu papel de líder por parte daqueles que as rodeiam:

"foi muito difícil para as pessoas esse reconhecimento de mudarem a entidade de referência que têm no local de trabalho" (P1)

"por vezes torna-se um pouco complicado impor respeito em obra, fazer cumprir as regras" (P2)

Note-se que para P1 a transição para uma posição de liderança implicou ir substituir o anterior chefe de equipe, o que poderá eventualmente dificultar nos liderados que integram essa equipe um processo de mudança do seu quadro de referência a nível de liderança. A dificuldade em ver o papel de líder reconhecido parece ser influenciada por questões de gênero e de idade, conforme se percebe no discurso de P2:

"para além de ser mulher, sou nova, e nem sempre sou levada a sério em todos os sentidos." (P2)

Este excerto chama a atenção para a importância de se considerar no processo de transição as características do líder. Mas também as dimensões contextuais, representadas aqui pela natureza da atividade ocupacional de P2 e que se verifica também com P1. Ambas desempenham funções em ambientes ainda tipicamente dominados pelo gênero masculino, algo que intensifica diferenças de gênero e machismo (Piterman, 2008). Isto é ainda coerente com a literatura que aponta que existe alguma dificuldade no reconhecimento de mulheres em posições de liderança por parte de colegas, em especial do sexo masculino (Brescoll, 2011).

Outra dificuldade identificada prende-se com as relações que estabelecem com subordinados, colegas e chefias e que se alteram tanto a nível formal, como informal: "a coisa mais complicada foi ter que reportar os acontecimentos ao meu chefe direto, ao diretor de produção" (P2)

"conquistar ali outra vez as pessoas a perceber o meu espaço, a perceber o espaço delas, a perceber ali aquele espaço mais informal que às vezes temos, que notamos que deixa de existir." (P1)

Considere-se igualmente a dificuldade de P1 em, agora na posição de líder, solicitar apoio a um supervisor em questões de trabalho, algo que se torna agora problemático e fonte de stress:

"aqui já não é esperado que isso seja feito; portanto, é o tal stress de perceber se estou a fazer isto bem e se não estiver, ninguém vai ver, ninguém vai rever." (P1)

As participantes referiram sentir discriminação em função do seu gênero, o que pode ser potenciador de pressão extra (Santos et al., 2018). Isso era visível, por exemplo, no facto de as pessoas recorrerem a elas para problemas a nível comportamental, em detrimento das questões técnicas:

"nunca senti nenhum tipo de discriminação por ser mulher de forma direta, mas de forma indireta noto.

Por exemplo, a pessoa que eu fui substituir, que fui suceder, era um homem e claramente que havia questões que Ihe colocavam, nomeadamente técnicas,

(...) noto que há coisas que me podiam perguntar, podiam consultar e que não o fazem, na parte mais técnica (...) em questões comportamentais claramente que me procuram, mas claramente não me procuram pela função que tenho, mas sim porque sou mulher $e$ vou perceber melhor" (P1)

Para P1 há sempre um afastamento das pessoas em relação a alguém que assume uma posição de liderança. Contudo, considera que essa distância se desvanece mais rapidamente no caso dos homens do que no das mulheres: 
"Mesmo os meus colegas, homens, que agora há pouco tempo assumiram funções de chefia, neste caso num nível hierárquico abaixo de mim, mas que também assumiram essas funções, nota-se que houve ali um afastamento (...) [Mas] conseguiram mais rapidamente aproximar-se das pessoas do que eu consegui. Eu vou conseguindo, mas nota-se que demora mais tempo e acho que ainda não consegui com toda a gente no escritório." (P1)

Conclui-se, assim, que o processo de transição para uma posição de liderança parece ser caracterizado por um empobrecimento da rede de apoio na organização, na medida em que ao subir na hierarquia a pessoa sente um afastamento das pessoas e, de certa forma, mantém-se isolada (mesmo que temporariamente). Isto poderá ser vivido com particular intensidade dada a inexperiência na nova posição, aliada ao facto de assumirem na totalidade a responsabilidade do cargo, sem terem oportunidade para dialogar ou solicitar apoio dos seus supervisores - seja porque eles não estão fisicamente disponíveis, seja porque é socialmente esperado que não o façam:

"a gente vai subindo, mais solidão vamos sentindo, não é? Isso é outra coisa que me estou a tentar adaptar e estou a tentar compreender porque somos um grupo pequeno aqui no [nome do local] e pá não é fácil esta questão porque efetivamente já não sou aquela pessoa a quem eles vão pedir conselhos ou que as pessoas vão tentar [...] parece que sou a referência para quando há problemas, mas não é aquela pessoa de referência para quando precisam de ajuda, o que é chato para mim, porque acho que não faz sentido" (P1)

Note-se que o isolamento das mulheres líderes no trabalho pode ser visto como potenciador de stress, tendo como consequência a falta de apoio formal e informal (Santos et al., 2018). Há cerca de vinte anos, Bellamy e Ramsay (1994) sinalizavam que um dos fatores subjacentes ao abandono de mulheres das organizações onde trabalhavam era a exclusão que sentiam por parte dos colegas, maioritariamente homens. E, mais recentemente, Nelson e Burke (2000) sublinharam que o isolamento no trabalho é um dos principais fatores que leva as mulheres em posições de liderança a despedirem-se, resultante também da falta de apoio a nível formal e informal.

A Figura 1 procura representar as diferentes dificuldades identificadas pelas participantes no processo de transição e as variáveis às quais essas dificuldades foram associadas.

Figura 1. Dificuldades e influências no processo de transição

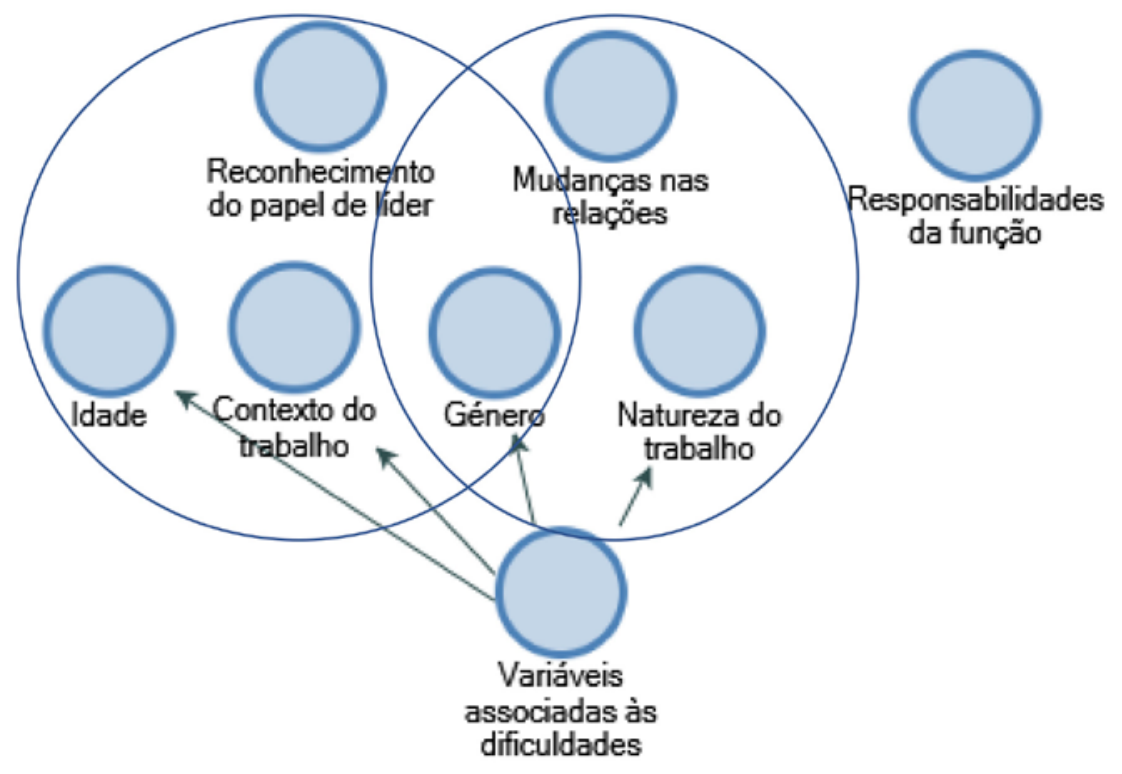


Note-se, contudo, que os estereótipos de gênero foram simultaneamente referidos pelas participantes como sendo potenciadores do seu desempenho, na medida em que as levam a procurar demonstrar que ser mulher não prejudica a sua capacidade de trabalho:

"dá mais força para conseguir mostrar que em nada tem que ser diferente e que, oh pá, dá na mesma. É um homem, uma mulher, o que for - dá na mesma e as coisas funcionam" (P1)

"(...) mas penso que consigo ultrapassar isso e que tem sido uma boa experiência, neste momento, ter esse papel de liderança. Tem me dado o estofo que eu preciso. (...) dá-me um certo gosto em saber que sou capaz de o fazer." (P2)

Ao mesmo tempo que há satisfação ao sentirem que são capazes de assumir a posição de liderança e de ultrapassar os obstáculos associados à mesma, a discriminação e as diferenças de gênero originam tristeza e mágoa:

"o que é engraçado, que é, magoa-me. Não vou mentir, magoa-me (...) deixa-me triste, mas não me deixa nem frustrada nem stressada, não. Tenho pena só. Estamos no século XXI, não é?" (P1)

A transição para a posição de liderança é vista pelas participantes como um voto de confiança da organização e o reconhecimento de competências, sendo estes factores mobilizados no processo de gestão da discriminação vivenciada:

"se alguém me escolheu para tomar este cargo de liderança é porque eu tenho capacidades para isso e pronto, muitas vezes, vejo que se depositaram essa confiança é porque eu consigo ser igual a eles, pelo menos, senão melhor" (P2)

Ou seja, a validação externa de líderes de nível hierárquico superior, na forma de atribuição de uma função de liderança, parece conferir maior segurança a esta participante, permitindo que se reconheça como competente para o desempenho da mesma.

\section{Representações acerca do processo de transição para uma posição de liderança}

A maioria das jovens mulheres que responderem ao questionário $(86,7 \%)$ acredita que o processo de transição para uma posição de liderança é diferente para homens e mulheres, sendo que apenas 13,3\% não acredita em diferenças de gênero neste processo. Este resultado vai ao encontro da literatura (Grant Thornton's International Business Report, 2018).

Em relação às dificuldades que consideram que uma mulher tem de enfrentar ao longo desse processo, referiram: reconhecimento do papel de líder; responsabilidades da função; e conciliação vida pessoal-trabalho. A dificuldade a nível do reconhecimento do papel de líder remete para a falta de reconhecimento da autoridade formal da líder e da legitimidade da sua promoção. O primeiro aspeto está então associado ao questionamento da credibilidade da mulher enquanto líder:

"descredibilização da sua autoridade" (PQ4) $)^{3}$

"questionamento da sua credibilidade como chefia"

"Desrespeito, falta de autoridade" (PQ19)

"Falta de aceitação" (PQ21)

As participantes referem ainda que as mulheres sentem que as pessoas à sua volta acreditam que a promoção para a posição de liderança não foi devida à sua competência:

"necessidade de se provar e mostrar que o lugar é merecido" (PQ6)

"Atribuírem a sua transição a fatores não associados com o seu desempenho e capacidade" (PQ10)

"nunca consideram que uma mulher chegou a um cargo de destaque por mérito, com esforço, dedicação, empenho e profissionalismo." (PQ19)

"querer fazer o melhor e assim comprovar que merece o cargo" (PQ3) 
Observa-se assim a crença na dificuldade em que seja reconhecido à mulher mérito pela promoção, algo que a literatura demonstra (Sanders, Hrdlicka, Hellicar, Cottrell, \& Knox, 2011). Para as jovens muIheres que integraram este estudo os estereótipos de gênero estão muito presentes no fenómeno da liderança feminina, no processo de transição para essa posição e de uma forma mais global:

"A questão do sexo é, só por si, uma dificuldade. Mesmo em pleno séc. XXI, existe um estigma do papel da mulher em liderança, especificamente a influência das hormonas que, segundo o estereótipo existente, influencia o processo de decisão" (PQ7)

"preconceito devido a ser mulher e ter-se ideia de que a liderança é para homens" (PQ3)

"há ainda muitos estereótipos associados à capacidade de liderança por parte do sexo feminino." (PQ10)

Estando as características atribuídas a um líder associadas a características vistas como masculinas, os homens acabam também por ser vistos como líderes naturais, o que vem reforçar as diferenças de gênero, conforme percecionado pelas participantes:

"os homens são vistos como líderes naturais logo a sua transição para uma posição de liderança não é visto como incomum ou errado" (PQ2)

"Existe o pressuposto de que os homens são melhores líderes." (PQ11)

"Devido à cultura e norma social, as mulheres tipicamente são vistas como menos capazes do que os homens" (PQ25)

"Existe um maior estigma sobre a capacidade de a mulher liderar, visto que consideram o homem quase como um líder inato." (PQ30)

O estereótipo segundo o qual os homens são líderes naturais leva a que as competências das muIheres para liderar sejam postas em causa (Grant Thornton's International Business Report, 2018), criando diferenças de gênero. Os estereótipos e a discriminação de gênero resultam em perceções negativas sobre a capacidade de liderança das mulheres (Grant Thornton's International Business Report,
2019) - veja-se o testemunho de PQ22 abaixo - e as mulheres tendem a comparar o seu desempenho com membros do gênero masculino e muitas vezes de os procurar ultrapassar (Davidson \& Cooper, 1983). Isso mesmo está claramente presente no discurso de PQ16:

"Ter de mostrar mais competências (pessoais e profissionais) uma vez que muitas vezes para uma mulher ser considerada para uma posição de liderança tem de mostrar mais provas que o homem" (PQ16)

"facilmente haver comentários de 'é mulher, por isso que não correu bem"' (PQ22)

As participantes consideram ainda que o processo de transição será vivido pelas mulheres mais intensamente e com mais barreiras, tendo em conta que é mais comum que um homem chegue a uma posição de liderança:

"Como é mais habitual que os homens cheguem à liderança, é normal que já não vivam tão intensamente o processo" (PQ3)

"cheio de barreiras e condicionalismos que talvez não fossem colocados se fosse do sexo masculino" (PQ19)

No que se refere às dificuldades associadas às responsabilidades da função, há referência às tarefas inerentes a uma posição de liderança, assim como a pressão de desempenho que é exercida e que é sentida pelas mulheres:

"pressão para fazer o seu melhor" (PQ5)

"perfeccionismo exigido e prazos muito breves" (PQ26)

"dificuldade de conciliação derivada da organização do seu próprio trabalho e o trabalho dos outros que terá que orientar" (PQ27)

As participantes referiram-se ainda à conciliação vida pessoal-trabalho, considerando que as mulheres terão menos tempo e disponibilidade para dedicar à vida profissional:

"a mulher assume um papel familiar marcadamente mais importante na nossa cultura" (PQ19) 
Ainda que atualmente já existam algumas políticas adotadas por empresas para reduzir as disparidades de gênero - pagamento de licenças de maternidade (59\%), flexibilidade de horários (57\%) e trabaIho em regime de part-time (54\%) (Grant Thornton's International Business Report, 2018), a mulher continua a desempenhar um importante papel a nível familiar, colocando-se-lhe mais dificuldades na gestão da relação trabalho-família, conforme é demonstrado na literatura (Brandão \& Lopes, 2017).

A transição de uma mulher para uma posição de liderança é vista como implicando uma mistura de emoções positivas e negativas. As participantes associam a este processo frustração, dúvida e receio, dadas as barreiras que se colocam e que importa ultrapassar, o facto de se tratar de um terreno desconhecido para a mulher e o acréscimo de responsabilidade e trabaIho associados à função:

"Cheio de frustrações" (PQ2)

"Penso que se trata de uma época complicada, na qual ela passa por várias emoções - como dúvida" (PQ11)

Ao mesmo tempo, referem-se à satisfação e ao orgulho, considerando que o processo será entendido pela mulher como um reconhecimento do seu trabalho e uma forma de se afirmar, o que parece ser coerente com o facto de um terço das mulheres européias entrevistadas no estudo desenvolvido pela Catalyst (2002) aspirarem à liderança de topo:

"Felicidade?" (PQ1)

"a transição é sempre vista como um reconhecimento do seu esforço" (PQ3)

"vivida com positividade" (PQ11)

"Com bastante orgulho" (PQ28)

As jovens universitárias consideram que nesse processo as mulheres encontram igualmente aspetos que as motivam para a ação, nomeadamente a vontade de alcançar os objetivos outrora definidos pelas mulheres:

"Vontade de fazer bem, querer superar-se" (PQ1)

"Os objetivos que a pessoa quer atingir" (PQ2)

"vontade de dar tudo" (PQ6)
"Vontade de mudança, afirmação pessoal, vontade de atingir o sucesso individual e coletivo" (PQ9)

"crescimento pessoal e profissional" (PQ13)

"Prémios de recompensa de objetivos; definição de objetivos de trabalho" (PQ14)

"raiva" (PQ15)

"grande motivação para fazer a diferença" (PQ28)

Considere-se em particular a raiva, que tendo sido referido por uma participante, gostaríamos de salientar pela sua diferença e que nos revela como as dificuldades podem ser interpretadas de forma distinta e motivar para a superação individual. Importa, contudo, perceber a que custo para o bem-estar das mulheres.

\section{Conclusões}

Este estudo permite-nos avançar com uma proposta preliminar de um modelo do processo de transição para uma posição de liderança, num processo que se percebe ser estruturado em diferentes fases, numa lógica de autonomização progressiva. Não foi possível com este estudo identificar se estas fases possuem um limite temporal, sendo isso algo que estudos futuros deverão procurar explorar. Parece-nos, assim, que será importante recolher dados junto de líderes que tenham iniciado o processo de transição entre dois a três anos, sendo a meta de dois anos frequentemente considerada para se avaliar o sucesso da transição (e.g., Keller \& Meaney, 2018). Esse intervalo temporal poderá permitir-nos avaliar em que medida se observa uma total autonomização do líder, assim como a forma como as dificuldades que identificamos aqui vão sendo geridas, se permanecem no tempo ou se emergem outros constrangimentos.

Conforme referido na introdução teórica, não foram identificados na literatura modelos acerca do processo de transição para uma posição de liderança, tendo-se, por isso recorrido ao modelo de integração organizacional proposto por Porter e colegas (1975). Note-se, contudo, que o modelo destes autores descreve o processo de alguém que não sendo membro da organização passa a integrá-la. Neste estudo focamos duas participantes que se tornaram 
líderes na organização onde já se encontravam integradas. Sendo certo que na fase de aprendizagem as participantes já conheciam as normas e a cultura da organização, há o acesso a nova informação sobre como desempenhar a função, observando-se a iniciação a um novo posto de trabalho. Na segunda fase do modelo de integração, o trabalhador inicia um período de trabalho experimental, que visa adaptá-lo à organização, assemelhando-se à fase de autonomização do processo de transição para uma posição de liderança. Nesta fase, que é caracterizada pelo início do desempenho de uma nova função na sua totalidade, a pessoa procura adaptar-se ao novo posto, mas também a toda a realidade subjacente ao mesmo (e.g., alterações nas relações laborais, indecisão quanto a tomadas de decisão). Por último, existe a fase em que o novo membro já se encontra adaptado ao contexto da organização, alterando os seus valores, relações e comportamentos. Da mesma forma, na fase de consolidação do processo de transição para uma posição de liderança a pessoa já se sente adaptada ao novo cargo, percebendose que as participantes associam a esta fase uma forma de fazer e de estar que representa uma nova normalidade no trabalho, mas ainda com incertezas.

Este trabalho sugere que a abordagem ao processo de transição aqui focado deverá seguir o modelo ecológico, no sentido de se considerar o processo, a pessoa, o contexto e o tempo (Bronfenbrenner \& Morris, 1998). E a importância de planear os processos de transição para posições de liderança, contrariando a tendência de muitas organizações deixarem a gestão do processo inteiramente à responsabilidade do líder em transição. Parece-nos importante desenhar programas de transição à medida do novo líder, o que vai, aliás, ao encontro de uma abordagem mais ecológica, conforme defendido. Note-se, a este propósito, que apesar de P1 já ocupar anteriormente uma posição de liderança na organização (pese embora de nivel inferior), associou dificuldades à transição, o que suporta a ideia de que a transição para uma posição de liderança requer sempre planejamento e suporte. Estas considerações poderão ser particularmente pertinentes quando se tratam mulheres que vivem este processo. Sendo este processo influenciado pelos estereótipos com base no gênero (conforme a vivência das participantes do estudo 1 e as perceções das do estudo 2), importa considerar que estes são fatores potenciadores de stress em mulheres em posições de liderança (Gardiner \& Tiggemann, 1999).
Importa realizar mais estudos que permitam tornar o modelo de transição proposto mais robusto, identificando nomeadamente se a proposta que aqui se apresenta descreve adequadamente o processo de transição de líderes em diferentes níveis da organização (e.g., líderes de topo em contraposição a líderes de primeiro nível, como são as participantes do estudo 1), assim como de diferentes gêneros. Esses estudos permitirão a definição de estratégias que as organizações poderão mobilizar para melhor apoiar a vivência deste processo de transição.

As três fases do processo de transição de mulheres para uma posição de liderança são caracterizadas por dificuldades e constrangimentos. Essas dificuldades são simultaneamente tidas como forças impulsoras, por permitirem à mulher demonstrar o seu valor enquanto profissional. Note-se ainda que apesar das participantes do estudo 2 não terem experienciado um processo de transição para uma posição de liderança, associaram a este dificuldades que vão ao encontro das experiências das participantes do estudo 1 , sendo que estas vivenciaram o processo focado. Isso sugere que a representação de jovens mulheres acerca deste processo organizacional está próxima da experiência de transição.

Este estudo apresenta algumas limitações que devem ser consideradas. Desde logo, o estudo 1 foca a experiência de duas participantes apenas. Face à dificuldade em acedermos em tempo útil a participantes que cumprissem com os critérios de inclusão definidos, procurou-se alcançar a saturação do participante; contudo, consideramos que esta não foi completamente alcançada. Seria importante, por isso, aceder a mais líderes, de forma a alcançar-se o ponto de saturação teórica. Para o futuro, será também pertinente realizar estudos que integrem homens e mulheres, de forma a perceber se o modelo proposto aplica-se independentemente do gênero e qual o papel desta e de outras dimensões na forma como o processo de transição é experienciado. Um outro aspeto também a considerar em estudos futuros é se o processo de transição tem especificidades para líderes que já estavam inseridos na organização em comparação àqueles que transitam de outras organizações. Note-se que no estudo 1 as duas participantes eram já trabalhadoras da organização onde se deu o seu processo de transição. Importa ainda notar que as participantes dos questionários responderam pensando em mulheres líderes sem se lhes ter solicitado que considerassem um nível de liderança em particular (e.g., de topo ou de $1^{\circ}$ linha). 
Este trabalho contribui para uma melhor definição do conceito de processo de transição para uma posição de liderança formal em contexto organizacional, avançando com uma primeira proposta da estrutura interna desse processo e as dificuldades que mulheres que vivenciam esse processo têm de gerir. Sugere ainda que mulheres que não viveram ainda este processo e que pertencem à geração millenial estão conscientes dos estereótipos de gênero presentes no contexto de trabalho no que se refere à liderança feminina. Sendo certo que essa consciência poderá torná-las mais competentes na identificação das manifestações desses estereótipos, capacitando-as para melhor lidar com as mesmas, importa reflectir (e investigar) se essas crenças terão efeitos negativos na auto-estima e sentido de competência das mulheres, desencorajando o investimento em posições de liderança. Importa intervir na sociedade, nomeadamente a nível da educação e formação, de forma a que se valorize a competência e o potencial de cada um para desempenhar funções de liderança (e outras), sem que os estereótipos de gênero limitem mulheres nem homens. Note-se que, ao contrário do senso comum, também mulheres querem chegar ao topo.

\section{Contribuições dos autores}

Brandão, C. participou da concepção, delineamento, análise dos dados da pesquisa, interpretação dos resultados, redação e aprovação da versão final do artigo científico. Santos, F. participou da concepção, delineamento, recolha e análise dos dados da pesquisa, interpretação dos resultados e redação do artigo científico. Peres, S. participou da concepção, recolha e análise dos dados da pesquisa e interpretação dos resultados.

\section{Conflitos de interesses}

Nenhum conflito financeiro, legal ou político envolvendo terceiros (governo, empresas e fundações privadas, etc.) foi declarado para nenhum aspecto do trabalho submetido (incluindo, mas não se limitando a subvenções e financiamentos, participação em conselho consultivo, desenho de estudo, preparação de manuscrito, análise estatística, etc.).

\section{Referências}

Aparna, J. (2014). By whom and when are women's expertise recognized? The interactive effects of gender and education in science and engineering teams. Administrative Science Quarterly, 59(2), 202239. Rcuperado de https://journals.sagepub. com/doi/abs/10.1177/0001839214528331. doi: $10.1177 / 0001839214528331$

Bass, B. M., \& Avolio, B. J. (1994). Shatter the Glass Ceiling: Women May Make Better Managers. Human Resource Management, 33(4), 549-560. Recuperado de https://onlinelibrary.wiley. com/doi/abs/10.1002/hrm.3930330405. doi: $10.1002 /$ hrm.3930330405

Bellamy, P. A., \& Ramsay, K. (1994). Barriers to women working in corporate management. Canberra: Australian Government Publishing Service.

Brandão, C. (2015). P. Bazeley and K. Jackson, Qualitative Data Analysis with NVivo (2nd ed.). Qualitative Research in Psychology, 12(4), 492-494. Recuperado de https:// www.researchgate.net/publication/282802998_P_ Bazeley_and_K_Jackson_Qualitative_Data_Analysis_with_ Nvivo_2nd_ed. doi: 10.1080/14780887.2014.992750

Brandão, C., \& Lopes, D. (2017). Conciliando a liderança e a maternidade: um estudo com recurso a histórias de vida. Revista Psicologia, Diversidade e Saúde, 6(4),1027-1043. Recuperado de https://www5.bahiana.edu.br/index. php/psicologia/article/view/1702. doi: 10.17267/23173394rpds.v6i4.1702

Brescoll, V. L. (2011). Who takes the floor and why: gender, power, and volubility in organizations. Administrative Science Quarterly, 56(4), 622-641. Recuperado de https://journals. sagepub.com/doi/abs/10.1177/0001839212439994. doi: 10.1177/0001839212439994

Bronfenbrenner, U., \& Morris, P. A. (1998). The ecology of developmental processes. In W. Damon \& R. M. Lerner (Eds.), Handbook of child psychology: Theoretical models of human development. Hoboken, NJ, US: John Wiley \& Sons Inc.

Catalyst (2002). Women in Leadership: A European Business Imperative. Retrieved from https://www.catalyst.org/ research/women-in-leadership-a-european-businessimperative/

Costa, C., Breda, Z., Pinho, I., Bakas, F., \& Durão, M. (2016). Performing a Thematic Analysis: An Exploratory Study about Managers' Perceptions on Gender Equality. The Qualitative Report, 21(13), 34-47. Recuperado de https:// nsuworks.nova.edu/tqr/vol21/iss13/4/ 
Daniel, A., \& Moudic, Y. (2010). Female and gender leadership: To which extents gender impacts on leadership and organizations in France? (MBA), Linnaeus University. Recuperado de http://www.diva-portal.se/smash/get/ diva2:322450/FULLTEXT01.pdf

Davidson, M. J., \& Cooper, C. L. (1983). Stress and the woman manager. Oxford: Martin Robin.

Dória, A., \& Brandão, C. (2016). The exercise of leadership in the feminine: the state of the art. Protocol of the International psychological applications conference and trends, Lisbon.

Eagly, A. H., \& Johannesen-Schmidt, M. C. (2001). The leadership styles of women and men. Journal of Social Issues, 57, 781-797. Recuperado de https://www.researchgate. net/publication/227528503_The_Leadership_Styles_of_ Women_and_Men. doi: 10.1111/0022-4537.00241

Eagly, A. H., Johannesen-Schmidt, M. C., \& Engen, M. L. (2003).

Transformational, transactional, and laissez-faire leadership styles: A meta-analysis comparing women and men. Psychological Bulletin, 129(4), 569-591. Recuperado de https://pdfs.semanticscholar.org/64ab/ af52dd802cf569379cf52bbb9822d56857aa.pdf. doi: 10.1037/0033-2909.129.4.569

Gardiner, M., \& Tiggemann, M. (1999). Gender differences in leadership style, job stress and mental health in male- and female- dominated industries. Journal of Occupational \& Organizational Psychology, 72(3), 301-315. Recuperado de https://onlinelibrary. wiley.com/doi/abs/10.1348/096317999166699. doi: $\underline{10.1348 / 096317999166699}$

Comissão para a Cidadania e a Igualdade de Género (2017). Igualdade de Género em Portugal. Boletim Estatístico 2017. Recuperado de https://www.cig.gov.pt/2018/02/igualdadegenero-portugal-boletim-estatistico-2017/

Grant Thornton's International Business Report. (2018). Gender balance remains elusive. Recuperado de https://www. grantthornton.global/en/press/press-releases-2018/ Gender-balance-remains-elusive/

Grant Thornton's International Business Report. (2019). Mouting pressure beginning to drive progress for women in senior leadership. Recuperado de https://www.grantthornton. global/en/press/press-releases-2019/mounting-pressurebeginning-to-drive-progress-for-women-in-seniorleadership/

Haile, S., Emmanuel, T., \& Dzathor, A. (2016). Barriers and challenges confronting women for leadership and management positions: review and analysis. International Journal of Business and Public Administration, 13(1), 36-51. Recuperado de https://bit.ly/2UwSOsG
Kanter, R. M. (1989). Work and Family in the United States: A Critical Review and Agenda for Research and Policy. Family Business Review: Russell Sage Foundation

Keller, S., \& Meaney, M. (2018). Successfully transitioning to new leadership roles. McKinsey \& Company, 1-8. Recuperado de https://www.mckinsey.com/ /media/McKinsey/ Business\%20Functions/Organization/Our\%20Insights/ Successfully\%20transitioning\%20to\%20new\%20 leadership\%20roles/Successfully-transitioning-to-newleadership-roles-web-final.ashx

Martin, J. (2015). Transformational and Transactional Leadership: An Exploration of Gender, Experience, and Institution Type. Libraries and the Academy, 15(2), 331-351. Recuperado de https://www.researchgate. net/publication/277626481_Transformational_and_ Transactional_Leadership_An_Exploration_of_Gender_ Experience_and_Institution_Type. doi: 10.1353/ pla.2015.0015

Nelson, D. L., \& Burke, R. J. (2000). Women executives: health, stress, and success. Academy of Management Executive, 14(2), 107-121. Recuperado de https://www.researchgate. net/publication/289691801_Women_executives_Health_ stress_and_success. doi: 10.5465/AME.2000.3819310

Piterman, H. (2008). Women in Management: The Leadership Challenge. Melbourne: Hannah Piterman.

Porter, L. W., Lawler, E. E., \& Hackman, J. R. (1975). Behavior in organizations. London: McGraw-Hill.

Sanders, M., Hrdlicka, J., Hellicar, M., Cottrell, D., \& Knox, J. (2011). What stops women from reaching the top? Confronting the tough issues. Recuperado de https://cew.org.au/wpcontent/uploads/2016/07/2011-CEW-Bain-report.pdf

Santos, F., Peres, S., \& Brandão, C. (2018, julho). Considerações metodológicas no estudo da liderança feminina. Atas do Congresso Ibero-Americano em Investigação Qualitativa, Fortaleza, CE, Brasil, 7. Recuperado de https:// proceedings.ciaiq.org/index.php/ciaiq2018/article/ view/1777/1902

Sargent, A. G., \& Schlossberg, N. K. (1988). Managing adult transitions. Training and Development Journal, 42(12), 58-60. Recuperado de https://eric.ed.gov/?id=EJ381396

Schlossberg, N. K. (2011). The challenge of change: the transition model and its applications. Journal of employment counseling, 48(4), 159-162.Recuperado de https:// onlinelibrary.wiley.com/doi/abs/10.1002/j.2161-1920.2011. tb01102.x. doi: 10.1002/j.2161-1920.2011.tb01102.x 